\title{
Effects of Invasive Jumping Worms (Amynthas spp.) On Microhabitat and Trophic Interactions of Native Herpetofauna
}

\section{Erin Renee Crone ( $\square$ Erin.Crone@colostate.edu )}

Colorado State University https://orcid.org/0000-0001-8300-5680

\section{Erin L Sauer}

University of Arkansas Fayetteville

\section{Bradley M Herrick}

UW-Madison: University of Wisconsin Madison

\section{David Drake}

University of Wisconsin-Madison

\section{Daniel L Preston}

Colorado State University

\section{Research Article}

Keywords: invasive earthworm, Amynthas, herpetology, trophic interactions, ecosystem engineer

Posted Date: July 6th, 2021

DOl: https://doi.org/10.21203/rs.3.rs-526527/v1

License: (c) (i) This work is licensed under a Creative Commons Attribution 4.0 International License. Read Full License

Version of Record: A version of this preprint was published at Biological Invasions on April 21st, 2022. See the published version at https://doi.org/10.1007/s10530-022-02781-y. 
7 Erin R. Crone ${ }^{1,2,5 *}$, Erin L. Sauer ${ }^{2,3,6}$, Bradley M. Herrick ${ }^{4,7}$, David Drake ${ }^{2,8}$, and Daniel L.

8 Preston $1,2,9$

9

$10{ }^{1}$ Department of Fish, Wildlife, and Conservation Biology, Colorado State University, Fort

11 Collins, Colorado 80521

$12{ }^{2}$ Department of Forest and Wildlife Ecology, University of Wisconsin, Madison, Wisconsin

1353706

$14{ }^{3}$ Department of Biological Sciences, University of Arkansas, Fayetteville, Arkansas, 72701

$15{ }^{4}$ University of Wisconsin-Madison Arboretum, Madison, Wisconsin 53711

16

17 Email addresses: ${ }^{5}$ erin.crone@colostate.edu, ${ }^{6}$ erinsauer10@gmail.com,

18 7bradley.herrick@wisc.edu, ${ }^{8}$ ddrake2@wisc.edu, ${ }^{9}$ dan.preston@colostate.edu

19

$20 *$ Corresponding author

21

22

23 
Abstract

Invasive species can affect native communities through multiple mechanisms, including ecosystem engineering and trophic interactions. In North America, invasive jumping worms

27 (Amynthas spp.) may alter microhabitats used by native herpetofauna or serve as a novel food resource for herpetofauna predators. We investigated effects of Amynthas on leaf litter microhabitat and trophic interactions of native herpetofauna using an outdoor mesocosm experiment, laboratory feeding trials, and field surveys of predator stomach contents in

31 Wisconsin, USA. In mesocosms, Amynthas reduced leaf litter biomass but did not have clear 32 effects on soil conditions ( $\mathrm{pH}$, moisture, and temperature) or survival of American toad metamorphs (Anaxyrus americanus). In laboratory trials, American toads preyed on Amynthas, though toads were less successful at capturing Amynthas compared with alternative prey, namely European earthworms (Lumbricus spp.) and crickets (Acheta domesticus). The differences in prey attack success were likely due to unique defensive behaviors of Amynthas. Amynthas also spent less time moving than Lumbricus, which was associated with later prey detection times by toads. Based on diet surveys, Amynthas are consumed by common garter snakes (Thamnophis 39 sirtalis) in southern Wisconsin. We did not find evidence of Amynthas consumption by American toads or red-bellied snakes (Storeria occipitomaculata), although additional surveys will be needed to definitively determine whether these taxa are consuming Amynthas. Our

42 findings highlight the importance of studying multiple mechanisms by which invasive species 43 affect native communities and suggest that unique anti-predator behaviors may influence how 44 Amynthas are incorporated into food webs as a novel prey resource.

45 Keywords: invasive earthworm, Amynthas, herpetology, trophic interactions, ecosystem engineer 46 


\section{Introduction}

Invasive species can affect recipient communities through a wide range of mechanisms, resulting in unforeseen consequences for native species. For instance, an invader may directly or indirectly influence trophic interactions, competition dynamics, disease transmission, or physical ecosystem structure (Crooks 2002; Carlsson et al. 2009; Vilcinskas 2015; Dueñas et al. 2018).

Effects on native community members are generally not isolated to a single type of interaction (Bennett et al. 2011; Kaemingk et al. 2017), complicating efforts to understand and predict consequences of species invasions. Untangling multiple mechanisms through which an invasive species affects native species may require a combination of research techniques.

Some invasive species serve as ecosystem engineers by altering the physical habitat structure to which native species have adapted (Crooks 2002; Ransom 2011). Native species may be directly affected by the structural changes or indirectly affected by resulting shifts in habitat conditions or community composition. Determining overall effects of ecosystem engineers in invaded communities can be complex. For example, an invasive algal ecosystem engineer (Halimeda incrassata) causes multidirectional effects within a Mediterranean Sea community; depending on the species, native fish may be attracted to, unaffected by, or driven away from the altered ecosystem (Vivó-Pons et al. 2020). Another invasive engineer, the North American beaver (Castor canadensis), reduces macroinvertebrate diversity in Chilean streams but increases overall macroinvertebrate biomass and productivity (Anderson and Rosemond 2007). Assessing net effects of invasive ecosystem engineers is further complicated when the invader also directly interacts with native taxa.

While the predatory roles of some invaders have received longstanding research attention, the potential for invaders to serve as novel prey has been recognized more recently. In 
some cases, nonnative prey can have positive population-level effects on native predators

71 (Carlsson et al. 2009). This can be particularly important if an invasive species outcompetes

72 native prey because it can mitigate the effect of reduced native prey availability (Dijkstra et al.

73 2013; Cava et al. 2018). For example, invasive round gobies (Apollonia melanostomus) in the

74 Great Lakes have been incorporated into diets of native predators including fish, birds, and

75 snakes (King et al. 2006; Hensler et al. 2008; Coleman et al. 2012) and have been linked to

76 population recovery of native snakes (King et al. 2006). Alternatively, if predators are unable to

77 effectively utilize an invasive species, due for instance to dietary specialization (Suárez et al.

78 2000) or prey defensive traits, this may lead to population declines in native predators. In a well-

79 studied example, the toxicity of invasive cane toads (Rhinella marina) to many native Australian

80 predators (Phillips et al. 2003) has resulted in population declines of native snakes, lizards, and

81 other species (Shine 2018).

82 Jumping worms (Amynthas and Metaphire spp.) are widespread invasive species in the

83 eastern United States and are recent invaders in several midwestern and northeastern states

84 (Chang et al. 2018). As only species of the Amynthas genus are considered here, the group will

85 hereafter be referred to as Amynthas. Originating in eastern Asia, including Japan and the Korean

86 Peninsula (Blakemore 2003, 2014), these earthworms were likely spread to the United States

87 through horticulture practices and use as fishing bait (Gates 1958; Görres and Melnichuk 2012).

88 Amynthas can reproduce parthenogenically, have an annual life span, and produce cocoons

89 throughout the summer months (Chang et al. 2016a). Invasive Amynthas may induce changes in

90 native communities through multiple mechanisms, though the overall effects of these changes on

91 native species are largely unknown. Amynthas live on the surface and upper few centimeters of

92 soil and consume detritus, which alters topsoil structure (Görres et al. 2019) and reduces leaf 
93 litter layers (Qiu and Turner 2017). Invasive Amynthas indirectly alter composition of leaf litter

94 invertebrate communities through mechanisms including resource competition (Snyder et al.

95 2011; Greiner et al. 2012; Gao et al. 2017) and have been known to outcompete previously

96 established nonnative earthworms (e.g., Apporectodea, Lumbricus, and Octolasion spp.) (Chang

97 et al. 2016b; Laushman et al. 2018). Additionally, invasive Amynthas potentially provide an

98 abundant novel prey source, but anti-predator defenses such as their characteristic "jumping"

99 behavior may make Amynthas challenging prey for native predators (Gorsuch and Owen 2014).

100 Few studies have documented the role of invasive Amynthas in food webs (but see Gorsuch and

101 Owen 2014 and Gao et al. 2017).

102

To examine how introduced Amynthas may affect native species through multiple

103 mechanisms, we conducted a mesocosm experiment, laboratory feeding trials, and field diet

104 surveys of native predators in Madison, Wisconsin, USA. In historically glaciated regions of the

105 northern United States, including the Madison area, there are no native earthworm species but

106 several established nonnative earthworms (e.g., Lumbricus spp., Aporrectodea spp., Octolasion

107 spp., Eisenia. spp.) (Hendrix and Bohlen 2002; Bohlen et al. 2004). Southern Wisconsin is also

108 home to native terrestrial herpetofauna that share habitat with and could potentially prey on

109 Amynthas, including American toads (Anaxyrus americanus), red-bellied snakes (Storeria

110 occipitomaculata), and common garter snakes (Thamnophis sirtalis) (Christoffel et al. 2008,

111 2009). In the current study, we asked 1) how invasive Amynthas worms, established nonnative

112 Lumbricus worms, and native American toads interact within leaf litter microhabitat, 2) how

113 predator-prey interactions with American toad predators compare for Amynthas prey and

114 alternative prey under laboratory conditions, and 3) whether native toads and snakes consume

115 Amynthas in the field. We predicted that 1) Amynthas would reduce leaf litter mass, soil 
116 moisture, and metamorphic toad survival, and increase soil temperature within mesocosms based

117 on known effects of Amynthas on forest floor habitat, 2) toads would have reduced success at

118 capturing Amynthas compared with alternative prey due to defensive behaviors of Amynthas, and

119 3) native toads and snakes would consume Amynthas, despite their status as a novel prey source

120 in this region.

121

122 Methods

Study site - We conducted the mesocosm experiment and diet survey at the University of

124 Wisconsin-Madison Arboretum (43.041293, -89.428252; hereafter referred to as the UW

125 Arboretum), a 1,200-acre restored public natural area and research center surrounded by urban

126 development. Amynthas were discovered in the UW Arboretum in 2013, and their range has

127 expanded rapidly (Laushman et al. 2018). Laboratory feeding trials were conducted at the

128 University of Wisconsin-Madison.

Mesocosm experiment - To examine effects of Amynthas on toad microhabitat, we

performed a $2 \times 2 \times 2$ factorial mesocosm experiment with the following treatments: 1) presence

131 or absence of 4 American toad metamorphs, 2) presence or absence of 20 Amynthas worms, and

132 3) presence or absence of 20 Lumbricus worms. We randomly assigned treatments to 50-liter

133 plastic mesocosms $(n=48$; rim diameter $=45 \mathrm{~cm}$, height $=38 \mathrm{~cm})$. We drilled holes in the bottom

134 of the mesocosms for drainage and raised $70 \%$ shade cloth over them to simulate canopy cover.

135 The mesocosms were covered on the bottoms with garden fabric and on the top with fiberglass

136 mesh lids to prevent worms and toads from escaping. We filled each mesocosm to an

137 approximate height of $30 \mathrm{~cm}$ with locally sourced screened topsoil from a nearby garden store,

138 then topped the soil with approximately $460 \mathrm{~g}$ of hand mixed leaf litter randomly collected from 
an Amynthas-free area of an oak-dominated forest in the UW Arboretum. Litter was composed predominantly of black oak (Quercus velutina, $\sim 66 \%$ by volume), white oak (Q. alba, 14\%), shagbark hickory (Carya ovata, 14\%), and black walnut (Juglans nigra, 3\%).

We collected Amynthas for the mesocosms by hand from beneath leaf litter, and we collected Lumbricus by applying a mustard solution to the soil (a method which draws worms to the surface by irritating the skin), after which they were rinsed with clean tap water. We only collected juveniles (worms lacking a clitellum) of all taxa, as Amynthas were predominantly in the juvenile life stage at the time. Worms were weighed (Table S1) and added to mesocosms within 12 hours of collection. Based on known species compositions in the area (Laushman et al. 2018, Price-Christenson et al. 2020), Amynthas worms added to mesocosms were a combination of Amynthas tokioensis and A. agrestis, and Lumbricus worms in the experiment were Lumbricus terrestris and L. rubellus.

We collected American toad metamorphs around three ponds in Madison. Toads were weighed (Table S1) and added to mesocosms in similar size cohorts to minimize competition effects. Toads were presumed to feed on naturally occurring springtails, beetles, ants, and mites observed within leaf litter. We also added 10 to 20 flightless fruit flies evenly to each mesocosm every two days throughout the experiment to ensure adequate prey availability.

We began the experiment on July 26, 2019 and took soil measurements weekly. We measured soil $\mathrm{pH}$ and temperature (Hanna Instruments Direct Soil Measurement pH/Temperature Meter HI 99121) and percent moisture (Extech Soil Moisture Meter MO750) by inserting meters at the soil surface to a depth of $\sim 10 \mathrm{~cm}$. On day 36 (Aug 31), we counted and weighed all toads and disassembled one toad + Amynthas + Lumbricus mesocosm to assess earthworm survival. Due to concerns about low numbers of observed earthworms, we added 10 
162

163

164

165

newly collected Amynthas to all Amynthas-treated mesocosms (for a total of 30 Amynthas worms added). On day 61 (Sep 25), we collected, counted, and weighed remaining toads and earthworms from all mesocosms. At this time, we also collected all leaf litter from each mesocosm and dried it in an oven for 24 hours at $80^{\circ} \mathrm{C}$ to quantify litter dry mass.

Feeding experiments - To examine predator-prey behavioral interactions between toads and Amynthas, we conducted two no-choice feeding trial experiments in September 2019 (hereafter referred to as Exp. 1 and Exp. 2). For both experiments, we used the same 12 American toads (mean mass $=16.9 \mathrm{~g}$; Table S2), collected from a jumping worm-free location (the UW-Madison Lakeshore Preserve). Toads were housed individually in 5.7-liter plastic storage bins with moist peat moss substrate and access to distilled water, and they were fasted for at least 48 hours prior to each experiment. We spot-cleaned habitats and replaced water daily. The two feeding trial experiments had slightly different designs. During each trial in Exp. 1, a toad was offered one live house cricket (Acheta domesticus), one Amynthas worm, or one Lumbricus worm. Each toad in Exp. 1 underwent one trial per prey type (36 total trials). Crickets were purchased from a local pet store and used as a positive control because they were expected to be readily consumed by toads. Amynthas were collected from the UW Arboretum, and Lumbricus (specifically, L. terrestris) were purchased from a local bait store. The average mass of the purchased Lumbricus (mean $=2.7 \mathrm{~g}$ ) was approximately 3 times the mass of the Amynthas $(0.9 \mathrm{~g})$ in Exp. 1 (Table S2). Because we did not want prey size differences to confound possible differences in earthworm-toad interactions, we then conducted a follow-up experiment (Exp. 2) in which we used only comparably sized Amynthas $($ mean $=0.6 \mathrm{~g})$ and Lumbricus (mean = $0.6 \mathrm{~g})$ prey (Table S2). In Exp. 2, Amynthas and Lumbricus were hand-collected in the UW Arboretum. Toads were offered one Amynthas worm or one Lumbricus worm per trial, and we conducted two 
185 trials per toad per prey type (48 total trials). In both experiments, trials were performed two days apart, and the order of prey for each toad was rotated between individual toads (Table S2).

Feeding trials were conducted in a clear plastic arena with a rectangular base $(29.7 \times 19.3$

$188 \mathrm{x} 20.3 \mathrm{~cm}$.) and brown paper was attached to the walls to minimize external stimuli. During each

189 trial, we placed a toad under a transparent cover in the arena for a five-minute acclimation

190 period. A pre-weighed prey item was placed in front of the toad, and the cover was removed. The 191 time of each attack or capture and total number of attacks were recorded. Attacks were defined

192 as any attempt (successful or not) by the toad to capture prey with or without physical contact. A 193 capture was an attack that resulted in the full consumption of a prey item. In Exp. 1, we removed 194 the toad after prey consumption or after 15 minutes if the prey had not been consumed. Based on 195 a lack of captures observed in the last 5 minutes of Exp. 1 trials, we reduced the time limit to 10 196 minutes for Exp. 2. Due to observed interspecific variation in worm movement in Exp. 1 (see 197 Discussion), we recorded each trial in Exp. 2 using an iPhone SE 2016 to quantify the proportion 198 of total trial time a worm spent moving (hereafter referred to as "prey movement proportion") 199 and the time at which the toad first visibly detected the earthworm (hereafter referred to as "prey 200 detection time"). The latter response variable was a consistently observed behavior in which a 201 toad would visibly turn its head toward the prey item, often followed by other characteristic 202 hunting behavior (e.g., crouching, stalking, attacking). Diet Surveys - To determine whether American toads or colubrid snakes were consuming 204 Amynthas worms in the field, we collected individual predators and nonlethally recovered their 205 stomach contents. We opportunistically captured predators during visual encounter surveys and 206 from beneath cover boards. Both survey methods were used in two disconnected areas of the UW 207 Arboretum: a jumping worm-invaded site ("invaded") and a site with no known Amynthas 
208 presence ("uninvaded"). The invaded site consisted of deciduous forest, oak savannah, prairie, 209 and mowed/garden spaces. The uninvaded site contained pine forest, deciduous forest, oak

210 savannah, and prairie. We surveyed the uninvaded site with the goal of comparing diets between

211 the two areas; however, the number of predators captured in each location was too low to

212 robustly analyze diet differences. To survey cover boards, we haphazardly placed a total of 50

213 corrugated tin and 20 plywood boards evenly in the two areas of the Arboretum. We checked

214 boards $\sim 2$ times a week from May to September 2020. Upon capture of each toad and snake, we

215 recorded mass and snout-vent length (SVL) (Fig. S2 and S3). We collected snake stomach

216 contents by gently palpating the stomach to induce regurgitation (Seigel et al. 1987). We

217 collected toad stomach contents by using gastric lavage methods (Solé et al. 2005) with clean

218 well water from an $8 \mathrm{Fr}($ diameter $=2.3 \mathrm{~mm})$ silicone veterinary feeding tube and $60 \mathrm{ml}$ plastic

219 syringe. Stomach contents were strained through a paper coffee filter. Retained prey items were

220 preserved in $70 \%$ ethanol and later identified visually using a dissecting microscope.

221 Analyses - To test our hypothesis that Amynthas would affect metamorphic toad

222 microhabitat and survival, we used linear models (lme4, Bates et al. 2015) to analyze treatment

223 effects on leaf litter dry mass, soil metrics $(\mathrm{pH}$, temperature, and log-transformed percent

224 moisture, and toad survival proportion within mesocosms. We modeled effects on leaf litter dry

225 mass using fixed effects for presence/absence of Amynthas, presence/absence of Lumbricus,

226 presence/absence of toads, and all interaction terms. For each soil response model, we used the

227 same treatment predictors and added a fixed effect for sample date (continuous) and a random

228 intercept for mesocosm identity to account for temporal variation and repeated measurements.

229 We modeled toad survival proportions using fixed effects for Amynthas, Lumbricus, and their 
230 interaction, as well as a fixed effect for sample date and a random intercept for mesocosm 231 identity.

232 We analyzed feeding experiment data to test our hypothesis that toads would be less 233 successful predators of Amynthas than of alternative prey. Exp. 1 and 2 were analyzed

234 independently. We analyzed the following response variables: attack number (total per trial), 235 success or failure of each attack ("attack success"), and prey movement proportion (movement 236 time/total trial time; Exp. 2 only). We tested for effects on each response using linear mixed 237 effects models (lme4, Bates et al. 2015) with a fixed effect for prey type. We included a random 238 intercept for toad identity for all responses except prey movement proportion because individual 239 prey items were only used once. We specified a Poisson distribution for the attack number 240 model, a binomial distribution for attack success, and Gaussian distributions for prey movement 241 proportion. We logit-transformed prey movement proportion to approximate a normal

242 distribution. For Exp. 1 only, every model was followed by Tukey-adjusted pairwise 243 comparisons (emmeans; Lenth et al. 2021) to directly compare between the three prey types. To 244 test the correlation between earthworm movement and toad hunting behavior in Exp. 2, we also 245 used a regression model with prey detection time (log-transformed) as the response, prey 246 movement proportion (logit-transformed) as a predictor, and toad identity as a random intercept. 247 All analyses were performed in R version 4.03 ( $\mathrm{R}$ Core Team 2020).

249 Results Mesocosm experiment - Both earthworm taxa altered leaf litter but did not affect soil

251 conditions or toad survival. Amynthas presence reduced dry leaf litter mass by $18.4 \mathrm{~g}(\mathrm{SE}=5.61)$ 252 on average relative to controls ( $1 \mathrm{~m}: \mathrm{t}=-3.28, \mathrm{p}=0.002)$ and Lumbricus reduced dry litter mass 
253

254

255

256

257

258

259

260

261

262

263

264

265

266

267

268

269

270

271

272

273

274

275

by $14.7 \mathrm{~g}(\mathrm{SE}=5.82)$ on average $(\mathrm{lm}: \mathrm{t}=-2.53, \mathrm{p}=0.016)($ Fig. 1$)$. Toads did not affect leaf litter mass $(\operatorname{lm}: \beta=-7.9 \mathrm{~g}, \mathrm{SE}=5.82, \mathrm{t}=-1.36, \mathrm{p}=0.183)$, and there were no significant interaction terms (Fig. 1). Sampling date affected the soil responses, but we did not detect significant effects of earthworms or toads (Fig. S1, Table S3). Toad survival across all treatments averaged 52\% on day 36 and 34\% at the end of the experiment on day 61. Neither Amynthas nor Lumbricus presence had significant effects on toad survival (glmer: Amynthas: $\beta=-17.08, \mathrm{SE}=12.9, \mathrm{t}=$ 1.32, $\mathrm{p}=0.202 ;$ Lumbricus: $\beta=-4.17, \mathrm{SE}=12.31, \mathrm{t}=-0.34, \mathrm{p}=0.739)$. The Amynthas-present mesocosms had lower mean survival than Amynthas-absent mesocosms on both day $36(13.3 \%$ lower) and day 61 (16.3\% lower), but this effect was not statistically significant (Fig. 2). Feeding experiments - In both experiments, toads attacked Amynthas more than other prey types, but attacks were less successful. Toads attacked crickets in most trials $(91.7 \%)$ and did so in comparably fewer trials for Amynthas (Exp. 1: 58.3\%, Exp 2: 41.7\%) and Lumbricus (Exp. 1: 33.3\%, Exp. 2: 54.7\%). The mean number of toad attacks on Amynthas in Exp. 1 was over $2 \mathrm{x}$ the number for crickets (pairs: ratio $=2.21, \mathrm{SE}=0.60, \mathrm{z}=2.94, \mathrm{p}=0.009$ ) and over $3 \mathrm{x}$ the number for Lumbricus (pairs: ratio $=3.82, \mathrm{SE}=1.26, \mathrm{z}=4.05, \mathrm{p}<0.001$ ) (Fig. 3A).

Similarly, the mean number of attacks on Amynthas in Exp. 2 was 3x the number for comparably sized Lumbricus (glmer: $\beta=1.11, \mathrm{SE}=0.25, \mathrm{z}=4.53, \mathrm{p}<0.001)$ (Fig. 3B). Mean attack success for Amynthas in Exp. 1 was over 13x lower than for crickets (pairs: odds ratio $=0.06, \mathrm{SE}=0.06$, $\mathrm{z}=-3.06, \mathrm{p}=0.006$ ) and $9 \mathrm{x}$ lower than for Lumbricus (pairs: odds ratio $=0.10, \mathrm{SE}=0.11, \mathrm{z}=-$

2.15, $\mathrm{p}=0.080$ ) (Fig. 3C). In Exp. 2, mean attack success for Amynthas was again 9x lower than for comparably sized Lumbricus (glmer: $\beta=-3.30, \mathrm{SE}=0.95, \mathrm{z}=-3.48, \mathrm{p}<0.001$ ) (Fig. 3D). During Exp. 2, prey movement proportion was lower for Amynthas than for Lumbricus (lm: $\beta=$ 2.18, $\mathrm{SE}=0.54, \mathrm{t}=-4.02, \mathrm{p}<0.001)($ Fig. 4A). Lastly, prey detection time in Exp. 2 occurred 
276 earlier during trials in which worms spent a larger proportion of time in motion (lmer: $\beta=-0.337$

$277 \pm 0.129 \mathrm{SE}, \mathrm{t}=-2.615, \mathrm{p}=0.012)($ Fig. 4B).

278 Diet surveys - We captured a total of 25 American toads, 35 red bellied snakes, and 44

279 common garter snakes. We captured 11 of the toads at the Amynthas-invaded site and 14 at the

280 uninvaded site. Only 1 toad was found under a cover board; all others were found incidentally.

281 No Amynthas were identified in toad stomach contents, and only one earthworm (unidentifiable)

282 was recovered from a toad in the Amynthas-uninvaded site. Other toad prey (reported as the \% of

283 the total prey items) included $25.3 \%$ snails ( 2 toads), $18.9 \%$ ants ( 2 toads), $9.5 \%$ millipedes (4

284 toads), $6.3 \%$ dipterans ( 4 toads), $5.2 \%$ springtails ( 5 toads), and 7.4\% unidentifiable prey (5

285 toads) (Table 1). "Unidentifiable prey" were considered too degraded for any level of

286 identification. Most snakes were captured at the Amynthas-invaded site (Table 1). Stomach

287 contents were recovered from $37 \%$ of red-bellied snakes (13 individuals), and all identifiable

288 prey consisted of nonnative slugs. Prey consisted of 62.5\% Deroceras reticulatum (6 snakes),

289 12.5\% Arion subfuscus ( 2 snakes), 18.8\% unidentifiable slugs ( 3 snakes), and 11.4\%

290 unidentifiable prey (4 snakes) (Table 1). Common garter snakes were the only species whose

291 stomach contents contained Amynthas. We recovered stomach contents from 34\% of common

292 garter snakes (15 individuals). Prey items consisted of 26.3\% Amynthas sp. (5 snakes), 26.3\%

293 Lumbricus sp. (3 snakes), and 21.1\% unidentifiable prey (4 snakes) (Table 1).

294 Discussion

295 Using mesocosm experiments, laboratory feeding trials, and field diet surveys, we were

296 able to increase understanding of the mechanisms through which a recent Amynthas invasion

297 affects native herpetofauna in the upper Midwest, USA. We found evidence that Amynthas act as

298 ecosystem engineers in leaf litter microhabitat and are a viable prey source for native 
299 herpetofauna, although their defensive behaviors may make them difficult to capture for some 300 species. Our findings do not provide strong support for Amynthas altering survival of litter301 dwelling herpetofauna via habitat modifications in the mesocosm experiment. Broadly, our 302 results suggest that combining experimental and field studies can be a useful approach to isolate 303 distinct mechanisms and quantify their importance in invaded communities. Amynthas reduced leaf litter biomass in our mesocosms, which supports prior research 305 (Greiner et al. 2012; Ziemba et al. 2015; Qiu and Turner 2017), but we did not detect significant 306 effects of Amynthas on soil pH, moisture, or temperature, or on metamorphic toad survival. 307 Previous results on how Amynthas affect soil conditions are mixed, but some studies have found Amynthas to be associated with increased pH (Laushman et al. 2018; Bethke and Midgley 2020), 309 altered thermal properties (Görres et al. 2019), and increased moisture loss (Görres et al. 2019). 310 In our study, remaining unconsumed leaf litter, the Amynthas cast layer within the mesocosms, 311 and ambient environmental conditions (e.g., light levels, relative humidity, and rainfall) may 312 have buffered soil from temperature and moisture changes. Mean toad survival was marginally 313 lower in Amynthas-present treatments, but we could not definitively link this result to Amynthas. 314 American toads are somewhat less susceptible to desiccation than other amphibians (Rittenhouse 315 et al. 2008), so results may have differed using other amphibian species. Earthworm invasions 316 have been linked to effects on other terrestrial amphibians, namely eastern red-backed 317 salamanders (Plethodon cinereus) (Maerz et al. 2009; Ransom 2011, 2012; Ziemba et al. 2015).

318 Other nonnative earthworms are associated with declines in salamander abundance in the 319 northeastern United States (Maerz et al. 2009), and consumption of leaf litter by Amynthas can 320 have sublethal effects on salamanders through increasing movement and thus energy 321 expenditures (Ziemba et al. 2015). Research comparing lethal and sublethal effects of Amynthas 
322 among multiple litter-dependent herpetofauna taxa would help assess ecosystem engineering

323 impacts across a broader native community.

324 In the feeding experiments, American toads hunted and attacked Amynthas, Lumbricus

325 and crickets, but toads were often unsuccessful attacking Amynthas compared with alternative

326 prey. We observed a higher number of attacks on Amynthas per trial because of the frequent

327 failed attacks. The repeated attacks on Amynthas suggest that low attack success was likely a

328 result of worm defensive behaviors rather than unpalatability (e.g., toxins or distasteful

329 compounds). Gorsuch and Owen (2014) found that, compared with other nonnative earthworms

330 (Aporrectodea longa and L. rubellus), Amynthas are more successful at evading capture by

331 nonnative wandering broadhead planarians (Bipalium adventitium), native seal salamanders

332 (Desmognathus monticola), and native ribbon leeches (Nephelopsis obscura). We observed three

333 distinct defensive behaviors by Amynthas: jumping, freezing, and tail separation. The jumping

334 defense is a behavior characterized by rapid undulations by an Amynthas worm to propel itself

335 away from a physical disturbance and potentially startle a predator (Gorsuch and Owen 2014).

336 Freezing was characterized by an immediate cease in movement for seconds to minutes at a time

337 following a physical disturbance. This behavior has not been previously reported in the literature

338 to our knowledge. As sight-based hunters, the toads commonly stopped displaying hunting

339 behaviors when worm movement ceased, making this an effective strategy. Tail separation was

340 the complete detachment of the tail region; this response occurred only once during our trials and

341 has also been reported in prior research (Gorsuch and Owen 2014). In our study the toad

342 consumed the separated tail and afterward captured and consumed the full worm, further

343 evidencing the palatability of Amynthas to toads. 
Overall movement patterns of Amynthas differed substantially from those of Lumbricus.

345 Amynthas movement was sporadic and varied, due in part to the freezing behavior, while

346 Lumbricus typically moved throughout most of the trial regardless of attacks. Additionally,

347 Amynthas movement sometimes only involved the head or mouthpart while the rest of the body

348 was stationary, which may have influenced toad hunting behavior. Worm movement patterns

349 were associated with toad hunting behavior; prey detection time and thus hunting activity

350 occurred earlier during trials with more active worms. Divergent life histories of Amynthas and

351 Lumbricus may help explain movement differences. Amynthas dwell on or near the soil surface

352 (epigeic to epi-endogeic) and are not known to create vertical burrows (Richardson et al. 2009;

353 Qiu and Turner 2017), while Lumbricus are shallow-dwelling to deep-burrowing (epi-endogeic

354 to anecic), depending on species (Shipitalo et al. 1988; Hale et al. 2006). So, for Lumbricus,

355 especially anecic species like L. terrestris, constant movement may itself be a defense

356 mechanism if its purpose is to seek a burrow to escape. Amynthas may have evolved more

357 diverse behavioral defenses because living on the soil surface results in more frequent exposure

358 to a wide range of terrestrial predators in their native range. Amynthas are highly abundant on the

359 soil surface in recently invaded areas (Laushman et al. 2018), so although they are likely harder

360 to capture than Lumbricus, they also may be more readily available to certain predators. While

361 laboratory trials can help us predict the outcome of novel trophic interactions between invasive

362 and native species, field studies are needed to reveal more clearly how invasive species integrate

363 into natural food webs.

364 In our herpetofauna diet surveys, we found Amynthas in the stomach contents of garter

365 snakes but not of American toads or red-bellied snakes. American toad stomach contents were

366 primarily composed of arthropods and gastropods, though one toad consumed a non-Amynthas 
367 earthworm. This aligns with prior findings that toads predominantly consume arthropod prey

368 (Smith and Bragg 1949; Bellocq et al. 2000; Bolek and Coggins 2000), but may opportunistically

369 prey on earthworms (Bush 1959). Earthworms have also been recorded in diets of toad species in

370 the related genus Bufo (Evans and Lampo 1996; Vallvé and Sánchez-Iglesias 2018; Kolenda et

371 al. 2019). Our sample size of American toads was relatively small, particularly in the Amynthas-

372 invaded area, so we cannot say with much certainty whether or not American toads are

373 consuming Amynthas in the field. Additionally, soft-bodied prey like earthworms are digested

374 more quickly and are therefore may be missed more often in visual stomach contents surveys

375 than arthropod prey (Pompanon et al. 2012). Based on our laboratory trials, American toads may

376 opportunistically consume Amynthas if they can capture them, but due to the inefficient hunting

377 behavior we observed, hunting Amynthas may result in a higher energy expense and lower prey

378 yield compared to alternative prey. This is important because Amynthas-induced extirpations of

379 earthworms including Lumbricus (Chang et al. 2016b; Laushman et al. 2018) and shifts in

380 broader invertebrate communities (Snyder et al. 2011; Gao et al. 2017) may change the prey

381 assemblages available to American toads and other species. More field-based research, including

382 quantification of energy flows into herpetofauna predators, would be needed to test this idea.

Our study provides the first evidence that we are aware of for common garter snake

384 consumption of Amynthas. Common garter snakes are highly opportunistic predators and are

385 known to consume nonnative prey including Lumbricus and Apporectodea earthworms (Virgin

386 and King 2019). While we have no data on common garter snake diets within the study area prior

387 to Amynthas invasion, we expect that as Amynthas compete with and reduce populations of other

388 earthworm taxa (Chang et al. 2016b; Laushman et al. 2018), Amynthas will become an

389 increasingly important component of common garter snake diets. This trend may have 
390 significance for other snakes of local conservation concern, such as the Butler's garter snake

391 (Thamnophis butleri), which is an earthworm specialist and is considered a species of

392 conservation concern in areas including Wisconsin (Wisconsin Department of Natural Resources

393 2017). Possibly, garter snakes and other predators that hunt using chemoreception may be able to

394 better overcome some of the defensive behaviors of Amynthas, such as jumping and freezing,

395 compared with predators that depend largely on sight-based hunting strategies (e.g., toads). Two

396 other taxa, native centipedes (families Cryptopidae and Scolopocryptopidae) and native rusty

397 crayfish (Oronectes rusticus), have displayed relative success at capturing invasive Amynthas

398 (Gorsuch and Owen 2014; Gao et al. 2017) and are also known to use chemoreception (Müller et

399 al. 2011; Kraus-Epley et al. 2015). Laboratory feeding trials testing chemoreception of snakes or

400 other species (see Burger 1991) with Amynthas prey could test this idea. Additionally, it is

401 unclear how the nutritional and energetic value of Amynthas as prey compare with other prey

402 species, which could be another informative research direction.

403

Interestingly, red-bellied snakes in our study consumed only nonnative slugs, which

404 corroborates previous research (Virgin and King 2019). Common garter and red-bellied snakes

405 are both widespread and relatively common in urban areas (Kjoss and Litvaitis 2001). The

406 dietary flexibility that allows predators to opportunistically switch to nonnative prey may also

407 help them succeed in urban areas because anthropogenic disturbances strongly affect prey

408 availability (Seress et al. 2018; Siqueira and Marques 2018). Accordingly, we suggest future

409 research focus on species-specific traits that make native predators successful at utilizing

410 nonnative prey.

411 Due to the potential for multiple, multidirectional effects of invasive species on native

412 communities, an integrative approach to invasive species research is essential. While teasing 
413 apart the individual mechanisms that affect native species can be complex, from a conservation

414 standpoint it is important to understand the net effects of invasive species interactions within

415 native communities. Our research helps to advance understanding of the effects of Amynthas on

416 native herpetofauna microhabitat and trophic interactions. More generally, our findings

417 emphasize the potential importance of nonnative species as novel food resources to native

418 consumers (Carlsson et al. 2009). This often-overlooked ecological role of nonnative species

419 should be evaluated alongside the more commonly studied effects of invaders as consumers,

420 competitors, and disease vectors to obtain a more holistic understanding of invasion biology.

421

422 Literature Cited

423 Anderson CB, Rosemond AD (2007) Ecosystem Engineering by Invasive Exotic Beavers

424

425

426

427

428

429

430

431

432

Reduces In-Stream Diversity and Enhances Ecosystem Function in Cape Horn, Chile.

Oecologia 154:141-153. https://doi.org/10.1007/s00442-007-0757-4

Bates D, Mächler M, Bolker B, Walker S (2015) Fitting Linear Mixed-Effects Models Using lme4. Journal of Statistical Software 67:1-48. https://doi.org/10.18637/jss.v067.i01

Bellocq M, Kloosterman K, Smith S (2000) The diet of coexisting species of amphibians in Canadian jack pine forests. Herpetological Journal 10:63-68

Bennett AE, Thomsen M, Strauss SY (2011) Multiple mechanisms enable invasive species to suppress native species. American Journal of Botany 98:1086-1094. https://doi.org/10.3732/ajb.1000177

433 Bethke P, Midgley M (2020) Amynthas spp. impacts on seedlings and forest soils are tree species-dependent. Biological Invasions 22:3145-3162. https://doi.org/10.1007/s10530-

435 $020-02315-4$ 
Blakemore RJ (2003) Japanese earthworms (Annelida: Oligochaeta): a review and checklist of species. Organisms Diversity \& Evolution 3:241-244. https://doi.org/10.1078/14396092-00082

Blakemore RJ (2014) Review and checklist of Korean earthworms (Oligochaeta : Megadrilacea). Zoology in the Middle East, 60 Supplement: Advances in Earthworm Taxonomy VI (Annelida: Oligochaeta), the Proceedings of the 6th International Oligochaete Taxonomy Meeting 7-16

Bohlen PJ, Scheu S, Hale CM, et al (2004) Non-native invasive earthworms as agents of change in northern temperate forests. Frontiers in Ecology and the Environment 2:427-435. https://doi.org/10.1890/1540-9295(2004)002[0427:NIEAAO]2.0.CO;2

Bolek M, Coggins J (2000) Seasonal occurrence and community structure of helminth parasites from the eastern American toad, Bufo americanus americanus, from Southeastern Wisconsin, U.S.A. Comparative Parasitology 67:202-209

Burger J (1991) Response to prey chemical cues by hatchling pine snakes (Pituophis melanoleucus): Effects of incubation temperature and experience. J Chem Ecol 17:10691078. https://doi.org/10.1007/BF01402934

Bush FM (1959) Foods of Some Kentucky Herptiles. Herpetologica 15:73-77

Carlsson NO, Sarnelle O, Strayer DL (2009) Native predators and exotic prey -an acquired taste? Frontiers in Ecology and the Environment 7:525-532. https://doi.org/10.1890/080093

Cava ZA, McMillan AM, Pennuto CM, Warren RJ II (2018) Hellbender Prey Preference Is Superseded by Native and Nonnative Prey Behavior. Journal of Herpetology 52:162-170. https://doi.org/10.1670/17-078 
Chang C-H, Johnston MR, Görres JH, et al (2018) Co-invasion of three Asian earthworms, Metaphire hilgendorfi, Amynthas agrestis and Amynthas tokioensis in the USA. Biol Invasions 20:843-848. https://doi.org/10.1007/s10530-017-1607-X

Chang C-H, Snyder BA, Szlavecz K (2016a) Asian pheretimoid earthworms in North America north of Mexico: An illustrated key to the genera Amynthas, Metaphire, Pithemera, and Polypheretima (Clitellata: Megascolecidae). Zootaxa 4179:495. https://doi.org/10.11646/zootaxa.4179.3.7

Chang C-H, Szlavecz K, Filley T, et al (2016b) Belowground competition among invading detritivores. Ecology 97:160-170. https://doi.org/10.1890/15-0551.1

Christoffel R, Hay R, Paloski R, Ramirez L (2008) Snakes of Wisconsin, 2nd edn. Wisconsin Department of Natural Resources

Christoffel R, Hay R, Paloski R, Wolfgram M (2009) Amphibians of Wisconsin, 2nd edn. Wisconsin Department of Natural Resources

Coleman JTH, Adams CM, Kandel M, Richmond ME (2012) Eating the Invaders: The Prevalence of Round Goby (Apollonia melanostomus) in the Diet of Double-Crested Cormorants on the Niagara River. Waterbirds 35:103-113. https://doi.org/10.1675/063.035.sp111

Crooks JA (2002) Characterizing ecosystem-level consequences of biological invasions: the role of ecosystem engineers. Oikos 97:153-166. https://doi.org/10.1034/j.16000706.2002.970201.x

Dijkstra JA, Lambert WJ, Harris LG (2013) Introduced species provide a novel temporal resource that facilitates native predator population growth. Biol Invasions 15:911-919. https://doi.org/10.1007/s10530-012-0339-1 
482 Dueñas M-A, Ruffhead HJ, Wakefield NH, et al (2018) The role played by invasive species in

483

484

485

486

487

488

489

490

491

492

493

494

495

496

497

498

499

500

501

502

503

interactions with endangered and threatened species in the United States: a systematic review. Biodivers Conserv 27:3171-3183. https://doi.org/10.1007/s10531-018-1595-X

Evans M, Lampo M (1996) Diet of Bufo marinus in Venezuela. Journal of Herpetology 30:7376. https://doi.org/10.2307/1564710

Gao M, Taylor MK, Callaham MA (2017) Trophic dynamics in a simple experimental ecosystem: Interactions among centipedes, Collembola and introduced earthworms. Soil Biology and Biochemistry 115:66-72. https://doi.org/10.1016/j.soilbio.2017.08.001

Gates GE (1958) On some species of the Oriental earthworm genus Pheretima Kinberg, 1867, with key to species reported from the Americas. American Museum Novitates 1888:

Görres JH, Martin C, Nouri-Aiin M, Bellitürk K (2019) Physical Properties of Soils Altered by Invasive Pheretimoid Earthworms: Does Their Casting Layer Create Thermal Refuges? Soil Systems 3:52. https://doi.org/10.3390/soilsystems3030052

Görres JH, Melnichuk RDS (2012) Asian Invasive Earthworms of the Genus Amynthas Kinberg in Vermont. Northeastern Naturalist 19:313-322. https://doi.org/10.1656/045.019.0212

Gorsuch JP, Owen PC (2014) Potential Edaphic and Aquatic Predators of a Nonindigenous Asian Earthworm (Amynthas agrestis) in the Eastern United States. Northeastern Naturalist 21:652-661. https://doi.org/10.1656/045.021.0415

Greiner HG, Kashian DR, Tiegs SD (2012) Impacts of invasive Asian (Amynthas hilgendorfi) and European (Lumbricus rubellus) earthworms in a North American temperate deciduous forest. Biol Invasions 14:2017-2027. https://doi.org/10.1007/s10530-0120208-y 
Hale CM, Frelich LE, Reich PB (2006) Changes in hardwood forest understory plant communities in response to European earthworm invasions. Ecology 87:1637-1649. https://doi.org/10.1890/0012-9658(2006)87[1637:cihfup]2.0.co;2

Hendrix PF, Bohlen PJ (2002) Exotic Earthworm Invasions in North America: Ecological and Policy Implications. BioScience 52:801-811. https://doi.org/10.1641/00063568(2002)052[0801:EEIINA]2.0.CO;2

Hensler S, Jude D, He J (2008) Burbot growth and diets in Lakes Michigan and Huron: an ongoing shift from native species to round gobies. American Fisheries Society Symposium 59:91-107

Kaemingk MA, Jolley JC, Paukert CP, et al (2017) Common carp disrupt ecosystem structure and function through middle-out effects. Mar Freshwater Res 68:718-731. https://doi.org/10.1071/MF15068

King RB, Ray JM, Stanford KM (2006) Gorging on gobies: beneficial effects of alien prey on a threatened vertebrate. Canadian Journal of Zoology 84:108-115. https://doi.org/10.1139/z05-182

Kjoss VA, Litvaitis JA (2001) Community structure of snakes in a human-dominated landscape. Biological Conservation 98:285-292. https://doi.org/10.1016/S0006-3207(00)00167-1

Kolenda K, Kuśmierek N, Kadej M, et al (2019) Road-killed toads as a non-invasive source to study feeding ecology of migrating population. Eur J Wildl Res 65:55. https://doi.org/10.1007/s10344-019-1292-4

Kraus-Epley KE, Lahman SE, Moore PA (2015) Behaviorally-Selective Chemoreceptor Lesions Reveal Two Different Chemically Mediated Orientation Strategies in the Rusty Crayfish, 
Orconectes Rusticus. Journal of Crustacean Biology 35:753-762. https://doi.org/10.1163/1937240X-00002378

528 Laushman KM, Hotchkiss SC, Herrick BM (2018) Tracking an invasion: community changes in 529 hardwood forests following the arrival of Amynthas agrestis and Amynthas tokioensis in 530 Wisconsin. Biol Invasions 20:1671-1685. https://doi.org/10.1007/s 10530-017-1653-4

531 Lenth RV, Buerkner P, Herve M, et al (2021) emmeans: Estimated Marginal Means, aka Least532 Squares Means. Version 1.5.5-1URL https://CRAN.R-project.org/package=emmeans

533 Maerz JC, Nuzzo VA, Blossey B (2009) Declines in Woodland Salamander Abundance 534 Associated with Non-Native Earthworm and Plant Invasions. Conservation Biology 535 23:975-981. https://doi.org/10.1111/j.1523-1739.2009.01167.x

Müller CHG, Sombke A, Hilken G, Rosenberg J (2011) 12 Chilopoda - Sense organs. In: The Myriapoda. Brill, pp 235-278

Phillips BL, Brown GP, Shine R (2003) Assessing the Potential Impact of Cane Toads on 539 Australian Snakes. Conservation Biology 17:1738-1747. https://doi.org/10.1111/j.1523-

541 Pompanon F, Deagle BE, Symondson WOC, et al (2012) Who is eating what: diet assessment 1739.2003.00353.x

544 Qiu J, Turner MG (2017) Effects of non-native Asian earthworm invasion on temperate forest 545 and prairie soils in the Midwestern US. Biol Invasions 19:73-88. https://doi.org/10.1007/s10530-016-1264-5

547 R Core Team (2020) R: A Language and Environment for Statistical Computing. R Foundation 548 for Statistical Computing, Vienna, Austria 
549 Ransom TS (2011) Earthworms, as ecosystem engineers, influence multiple aspects of a

550

551

552

553

554

555

556

557

558

559

560

561

562

563

564

565

566

567

568

569

570

571

salamander's ecology. Oecologia 165:745-754. https://doi.org/10.1007/s00442-0101775-1

Ransom TS (2012) Comparison of direct, indirect, and ecosystem engineering effects of an earthworm on the red-backed salamander. Ecology 93:2198-2207. https://doi.org/10.1890/11-2024.1

Richardson DR, Snyder BA, Hendrix PF (2009) Soil Moisture and Temperature: Tolerances and Optima for a Non-Native Earthworm Species, Amynthas agrestis (Oligochaeta: Opisthopora: Megascolecidae). sena 8:325-334. https://doi.org/10.1656/058.008.0211

Rittenhouse TAG, Harper EB, Rehard LR, Semlitsch RD (2008) The Role of Microhabitats in the Desiccation and Survival of Anurans in Recently Harvested Oak-Hickory Forest. Copeia 2008:807-814. https://doi.org/10.1643/CH-07-176

Seigel RA, Collins JT, Novak SS (1987) Snakes: ecology and evolutionary biology. Macmillan

Seress G, Hammer T, Bókony V, et al (2018) Impact of urbanization on abundance and phenology of caterpillars and consequences for breeding in an insectivorous bird. Ecological Applications 28:1143-1156. https://doi.org/10.1002/eap.1730

Shine R (2018) Cane Toad Wars. University of California Press

Shipitalo MJ, Protz R, Tomlin AD (1988) Effect of diet on the feeding and casting activity of Lumbricus terrestris and L. rubellus in laboratory culture. Soil Biology and Biochemistry 20:233-237. https://doi.org/10.1016/0038-0717(88)90042-9

Siqueira LHC, Marques OAV (2018) Effects of Urbanization on Bothrops jararaca Populations in São Paulo Municipality, Southeastern Brazil. Journal of Herpetology 52:299-306. https://doi.org/10.1670/17-021 
572 Smith CC, Bragg AN (1949) Observations on the Ecology and Natural History of Anura, VII.

573

574

575

576

577

578

579

580

581

582

583

584

585

586

587

588

589

590

591

592

Food and Feeding Habits of the Common Species of Toads in Oklahoma. Ecology

30:333-349. https://doi.org/10.2307/1932614

Snyder BA, Callaham MA, Hendrix PF (2011) Spatial variability of an invasive earthworm (Amynthas agrestis) population and potential impacts on soil characteristics and millipedes in the Great Smoky Mountains National Park, USA. Biol Invasions 13:349358. https://doi.org/10.1007/s10530-010-9826-4

Suárez AV, Richmond JQ, Case TJ (2000) Prey Selection in Horned Lizards Following the Invasion of Argentine Ants in Southern California. Ecological Applications 10:711-725. https://doi.org/10.1890/1051-0761(2000)010[0711:PSIHLF]2.0.CO;2

Vallvé Á, Sánchez-Iglesias I (2018) Composition of the diet of the Iberian common toad (Bufo spinosus, Daudin, 1803) in central Spain. Basic and Applied Herpetology 32:19-27. https://doi.org/10.11160/bah.95

Vilcinskas A (2015) Pathogens as Biological Weapons of Invasive Species. PLOS Pathogens 11:e1004714. https://doi.org/10.1371/journal.ppat.1004714

Virgin EE, King RB (2019) What Does the Snake Eat? Breadth, Overlap, and Non-native Prey in the Diet of Three Sympatric Natricine Snakes. Herpetological Conservation and Biology $14: 132-142$

Vivó-Pons A, Alós J, Tomas F (2020) Invasion by an ecosystem engineer shifts the abundance and distribution of fish but does not decrease diversity. Marine Pollution Bulletin 160:111586. https://doi.org/10.1016/j.marpolbul.2020.111586 
593 Wisconsin Department of Natural Resources (2017) Wisconsin Butler's Gartersnake Species Guidance. Bureau of Natural Heritage Conservation, Wisconsin Department of Natural Resources PUB-ER-665

596 Ziemba JL, Cameron AC, Peterson K, et al (2015) Invasive Asian earthworms of the genus 597 Amynthas alter microhabitat use by terrestrial salamanders. Can J Zool 93:805-811.

598 https://doi.org/10.1139/cjz-2015-0056

599

600

601 Acknowledgements

602 We thank the University of Wisconsin-Madison Arboretum for providing funding and support

603 for this research. We thank the National Science Foundation Graduate Research Fellowship 604 Program for providing support under Grant No. DGE-1747503. Any opinions, findings, and 605 conclusions or recommendations expressed in this material are those of the authors and do not 606 necessarily reflect the views of the National Science Foundation. Support was also provided by 607 the Graduate School and the Office of the Vice Chancellor for Research and Graduate Education 608 at the University of Wisconsin-Madison with funding from the Wisconsin Alumni Research 609 Foundation. We would also like to thank E. Plumier and C. Lewis for help with setup and animal 610 collection, and A. Miller-ter Kuile, L. Falke, D. Trovillion, L. Bailey, L. Angeloni, and N. 611 Tutland for assistance with manuscript preparation.

\section{Declarations:}

\section{$614 \quad$ Funding}


615 This study was funded by the University of Wisconsin-Madison Arboretum Research Fellowship

616 (2019 and 2020) and the National Science Foundation Graduate Research Fellowship Program

617 (Grant No. DGE-1747503).

618 Conflicts of interest

619 The authors declare no conflicts of interest.

620 Availability of data and material

621 All data sets and statistical code used in this study will be made freely available prior to

622 publication and is available upon request.

623 Authors' contributions

624 EC, DP, BH, and DD conceived the ideas and designed the studies. EC, ES, and DP helped with

625 set up mesocosm setup and statistical analyses. EC collected data and wrote the manuscript draft.

626 All authors contributed to revisions.

627 Ethics approval

628 All use of research animals was approved by UW-Madison College of Agriculture and Life

629 Sciences IACUC (Protocols A006183-A02 and A006186-A03). Permits were obtained from the

630 Wisconsin Department of Natural Resources for sampling and collection (\#SRLN-19-32 and

631 \#SRLN-20-12).

632 Consent to participate

633 Not applicable.

634 Consent for publication

635 All authors provide their consent for publication.

636

637 
639 Figure 1. Mean dry mass of leaf litter in the 2019 mesocosm experiment at for each treatment 640 group: American toad (Anaxyrus americanus) presence, Amynthas presence, and Lumbricus 641 presence. Error bars represent the standard error of each treatment mean

642 Figure 2. Mean percentage of American toad metamorphs (Anaxyrus americanus) surviving in a 643 mesocosm experiment at each sampling date (Aug 31 and Sep 25, 2019) for each earthworm 644 treatment group. Error bars represent the standard error of each treatment mean

645 Figure 3. Summary of attack data from September, 2019 feeding trial experiments. A) Mean total 646 number of attacks by toads per trial on crickets (Acheta), Amynthas, and Lumbricus in Exp. 1. B) 647 mean total number of attacks by toads per trial on Amynthas and Lumbricus in Exp. 2. C) mean 648 success rate of attacks by toads per trial (successful attacks/unsuccessful attacks) for each prey 649 type in Exp. 1, and D) mean success rate of attacks by toads per trial (successful

650 attacks/unsuccessful attacks) for each prey type in Exp. 2. Error bars represent the standard error 651 of each treatment mean

652 Figure 4. A) Boxplot showing prey movement proportion (time moving/total trial time) for 653 Amynthas and Lumbricus prey in feeding experiment 2, conducted in September 2019. The 654 center lines represent the median proportions. B) Linear model of log-transformed prey detection 655 time (time at which toad was observed to first detect prey) predicted by logit-transformed prey 656 movement proportion in feeding experiment 2 , which reflects a statistically significant negative 657 relationship $(\mathrm{p}=0.012)$. The grey area represents a $95 \%$ confidence interval

658 Table 1. Prey identified in stomach contents of herpetofauna predators from 2020 field diet 659 surveys at the UW Arboretum (Madison, WI, USA). Prey count is the total number of a prey 660 type across all predator individuals of one species. Predator count is the total number of 661 predators that consumed one or more of each prey type. 


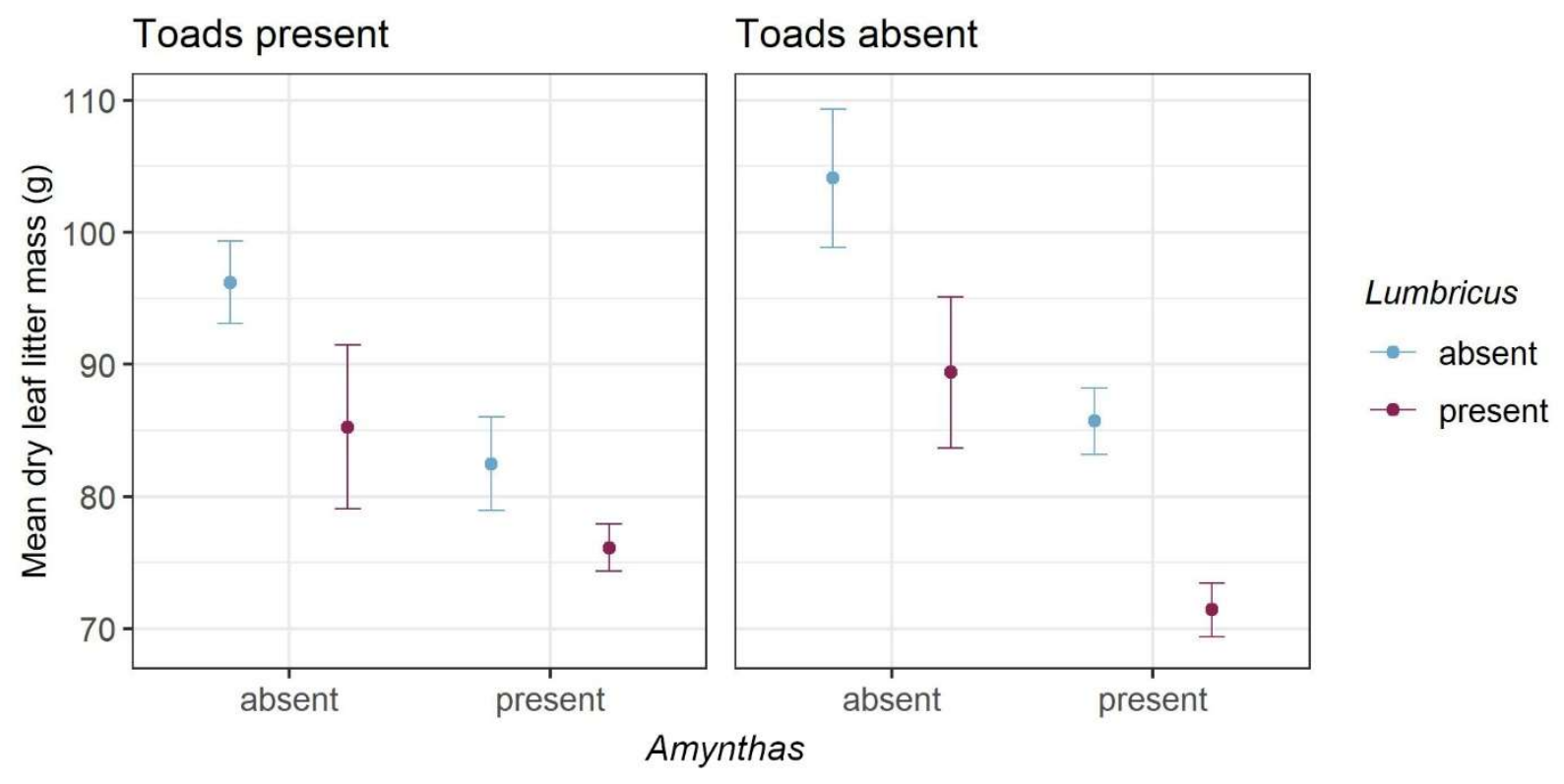




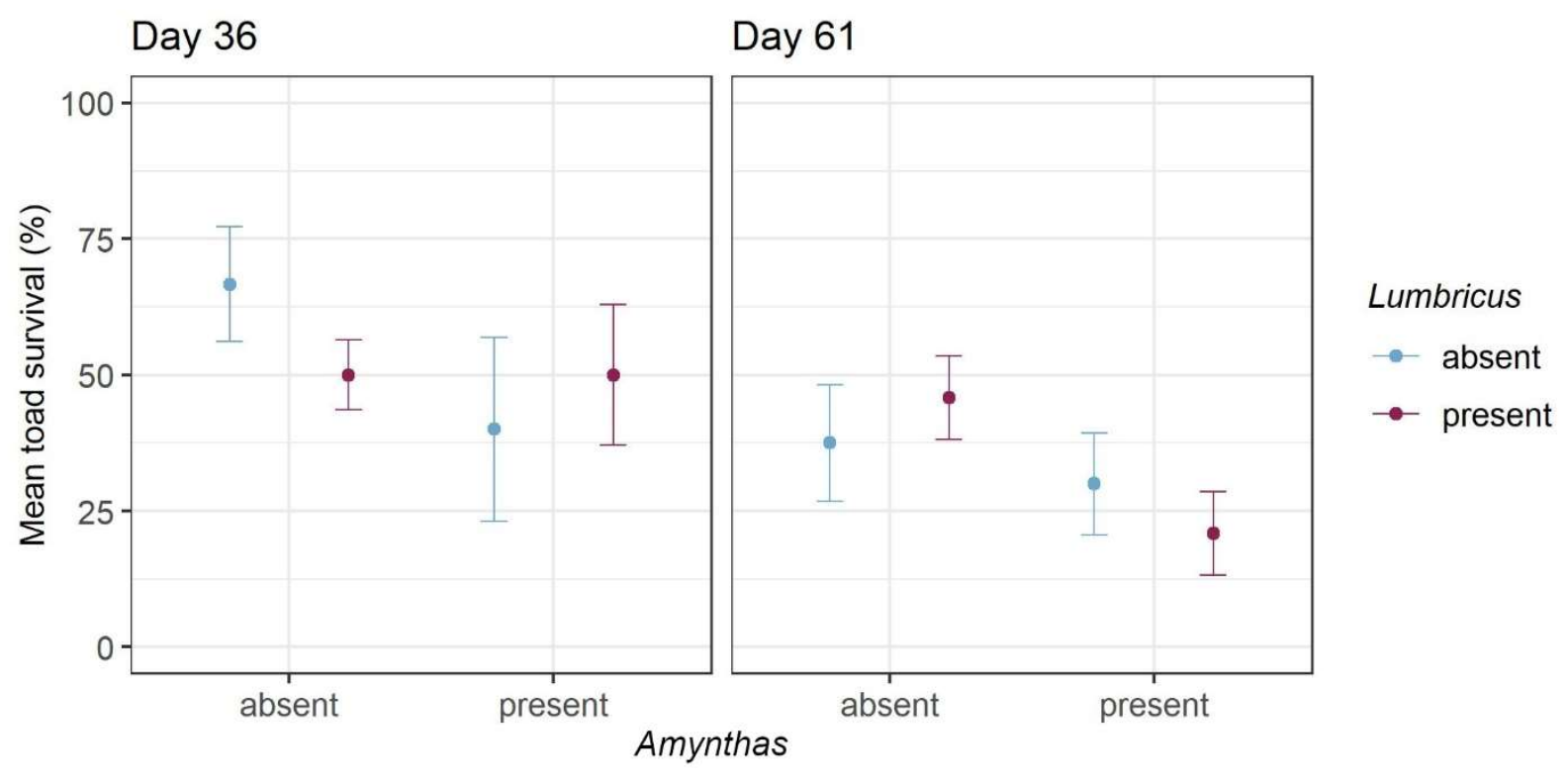




\section{Experiment 1}
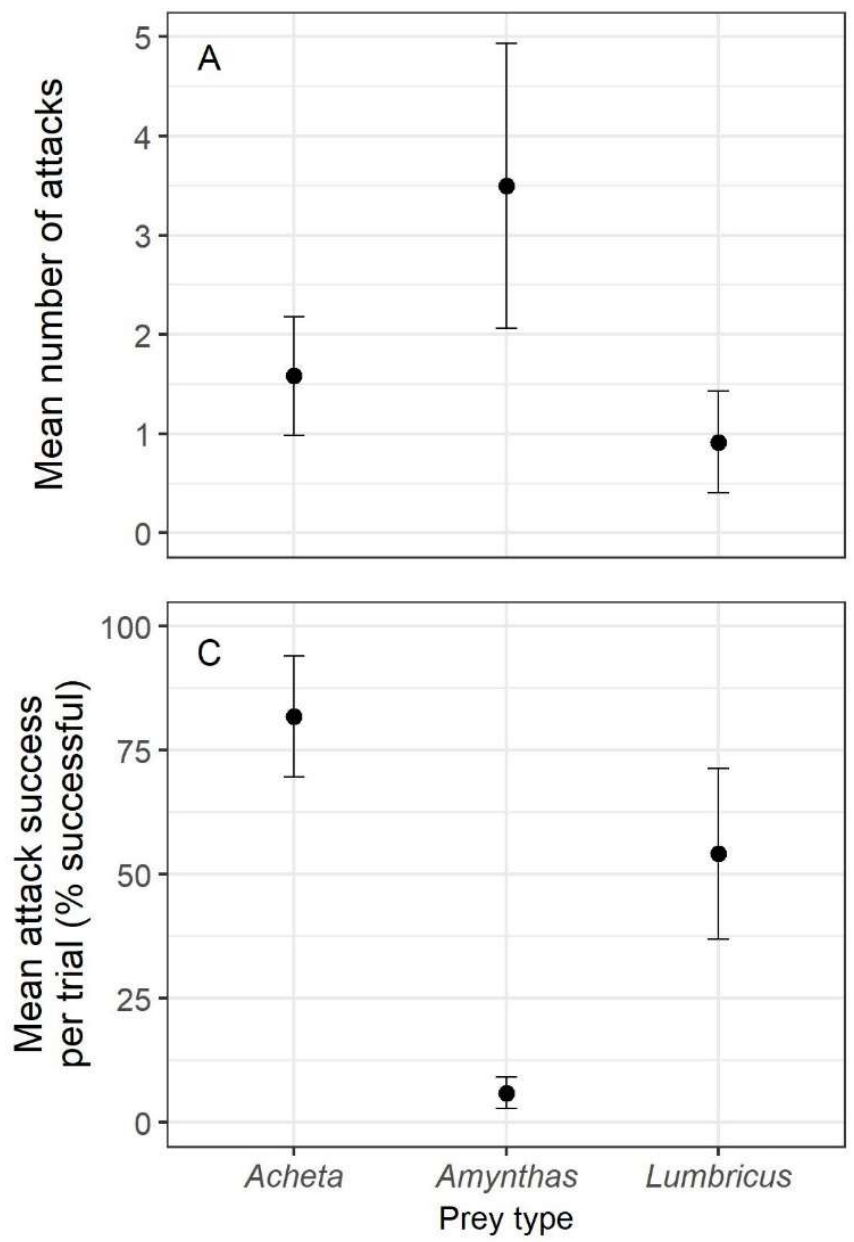

\section{Experiment 2}
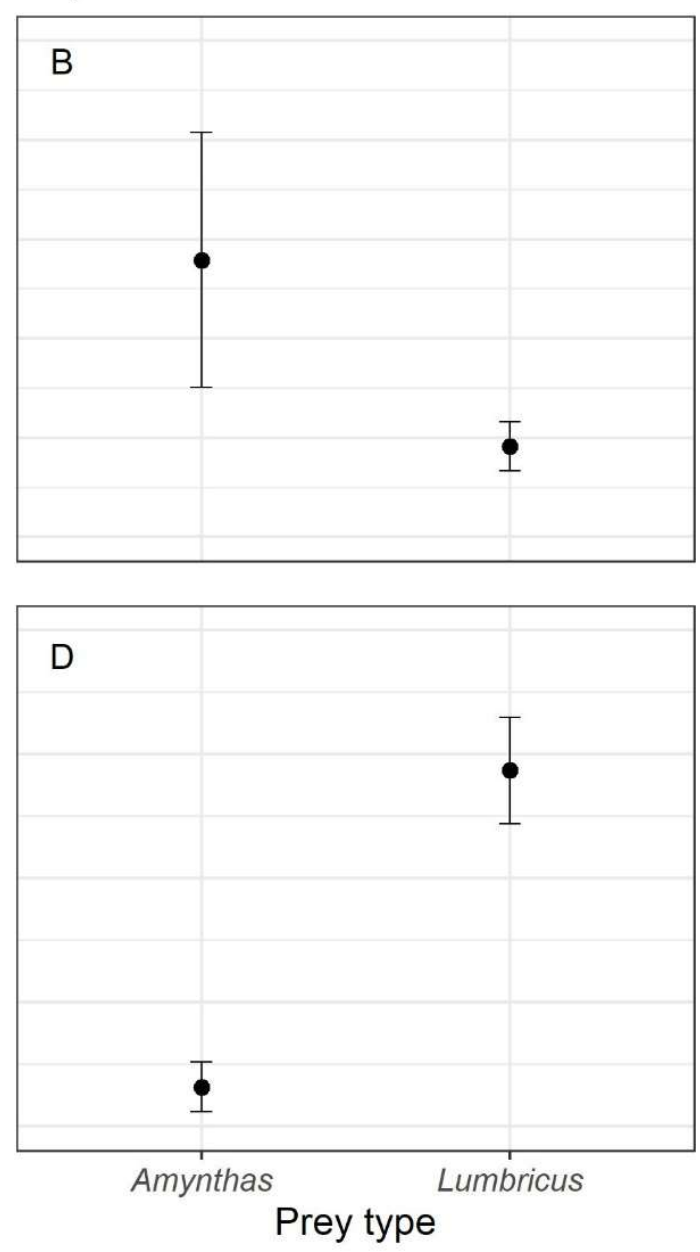

664 

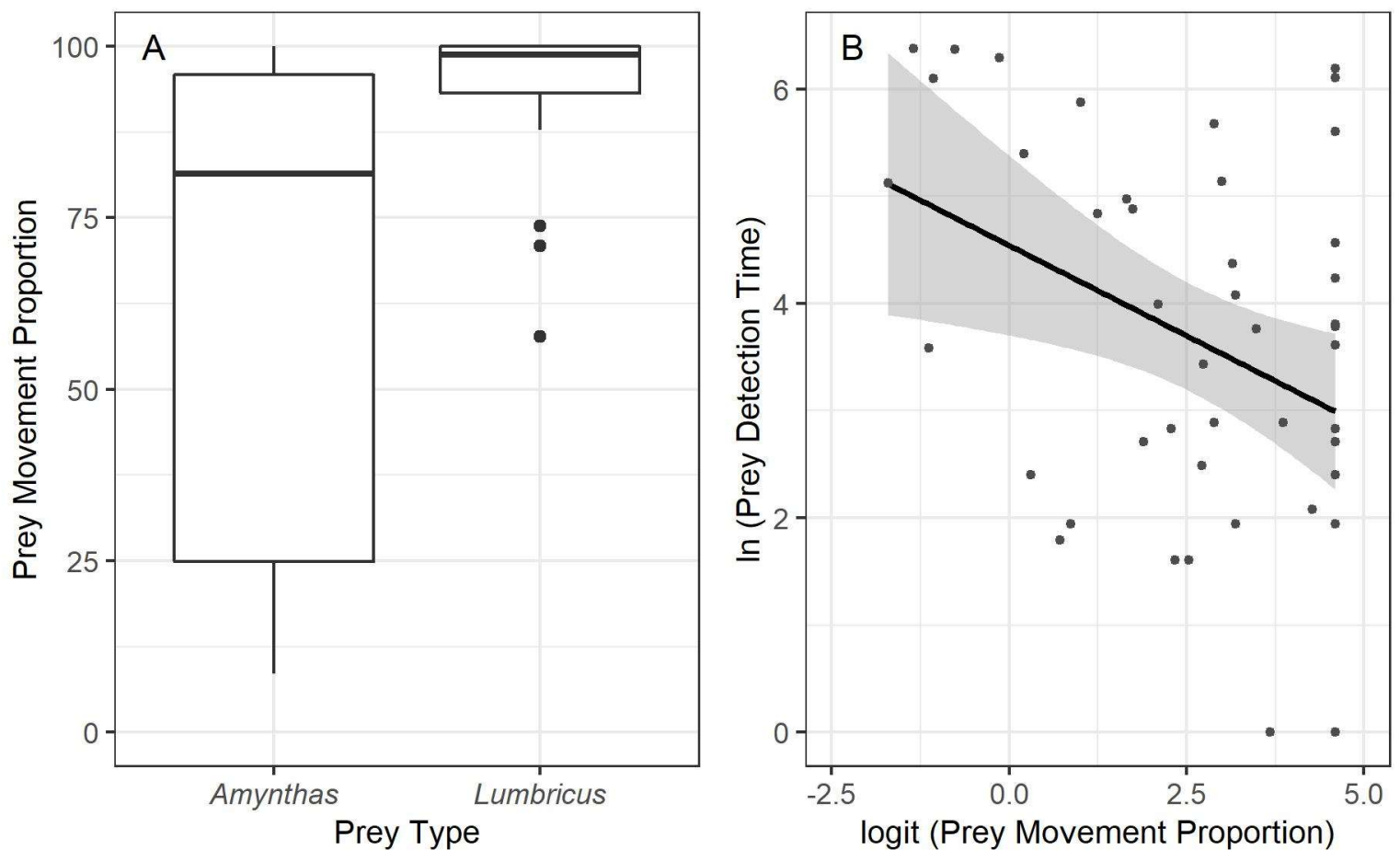


\begin{tabular}{|c|c|c|c|}
\hline Species & Prey Type & Prey Count & Predator Count \\
\hline \multirow{18}{*}{$\begin{array}{l}\text { Anaxyrus } \\
\text { americanus }(\mathrm{n}= \\
25)\end{array}$} & Araneae & 4 & 3 \\
\hline & Blattodea & 9 & 2 \\
\hline & Chilopoda & 1 & 1 \\
\hline & Coleoptera & 5 & 4 \\
\hline & Collembola & 5 & 5 \\
\hline & Diplopoda & 9 & 4 \\
\hline & Diptera (adult) & 1 & 1 \\
\hline & Diptera (larva) & 6 & 4 \\
\hline & Gastropoda (snail) & 24 & 2 \\
\hline & $\begin{array}{l}\text { Gastropoda (slug - Deroceras } \\
\text { reticulatum) }\end{array}$ & 1 & 1 \\
\hline & Hymenoptera (Formicidae) & 18 & 4 \\
\hline & Hymenoptera (unknown) & 1 & 1 \\
\hline & Isopoda & 1 & 1 \\
\hline & Nematoda & 1 & 1 \\
\hline & Oligochaeta & 1 & 1 \\
\hline & Trombidiformes & 1 & 1 \\
\hline & unidentified & 7 & 5 \\
\hline & no prey recovered & - & 7 \\
\hline \multirow{5}{*}{$\begin{array}{l}\text { Storeria } \\
\text { occipitomaculata } \\
(\mathrm{n}=35)\end{array}$} & Arion subfuscus & 2 & 2 \\
\hline & Deroceras reticulatum & 11 & 7 \\
\hline & unidentified slug & 3 & 3 \\
\hline & unidentified & 1 & 1 \\
\hline & no prey recovered & - & 22 \\
\hline \multirow{6}{*}{$\begin{array}{l}\text { Thamnophis } \\
\text { sirtalis }(\mathrm{n}=44)\end{array}$} & Amynthas spp. & 5 & 5 \\
\hline & Anaxyrus americanus & 5 & 5 \\
\hline & Lumbricus spp. & 5 & 3 \\
\hline & unidentified earthworm & 2 & 2 \\
\hline & unidentified & 2 & 2 \\
\hline & no prey recovered & - & 29 \\
\hline
\end{tabular}




\section{Supplementary Files}

This is a list of supplementary files associated with this preprint. Click to download.

- CroneSupplementaryInformation.pdf 